\title{
Computational Design Thinking for first year architectural design studios.
}

\author{
Simos Vamvakidis ${ }^{l}$ \\ ${ }^{1}$ Plymouth University \\ 1'yerasimo@gmail.com
}

\begin{abstract}
Digital design tools are actually changing the way we design architecture, even if we never choose to use any software. This paper examines and proposes an initial design approach towards Computational Design Thinking for first-year architecture students, without the use of any parametric software. It investigates some of the main points of a Computational Design Thinking approach and then proposes a method for teaching design studios. The method refers to digital design tools / software we use as architects, introducing ways to manipulate physical form, almost the same way that digital design software manipulates digital models. Finally, the paper documents the outputs and evaluates the application of this method in teaching first year design studio in a UK university.
\end{abstract}

Keywords: Diagram, Generative Design, Transformations, Physical and Digital Modelling, Computational Design Thinking

\section{INTRODUCTION}

The term Computational Design Thinking, initially introduced by Terzidis (2006), is used to describe an approach where digital and parametric design media used as design tools for architectural synthesis (and not as mere representational tools, which Terzidis (2006) calls "Computerisation"). The method discussed in this paper directly aligns with Pask (1969) and the Cybernetics theory; especially the needed mapping of any steps in a design process, as well as adding feedback in a process that is cyclical, as the systems theory by Wiener (1969) proposed.

The logic of transformations, that digital architecture theory and generative architectural design drew form the theory of form creation Morphogenesis- in biology and Thompson (1917), is another point of reference in form-finding. Today, Leach (2009) discusses how the theory of Morpho- genesis has crucially affected digital and parametric design theory and practice. At the same time, the method uses an important tool that allows architects to map a design process; the diagram, as Eisenman (1999) and Lynn (1999) introduced. The diagram has now become a design method globally.

Menges (2011) proposed that any process of form-finding should include the instructions of the process itself. Also the complexity inherent to parametric or algorithmic design relies to a great extent on the codification of form (Marcos 2010). For this reason, in the discussed method, the commands used to manipulate form are documented in each step, as an analogue way to write a "code" for the transformations. The steps to be followed in Phase 2 of the method application include a final CAD-CAM convergence (Kolarevic 2003). 


\section{EDUCATIONAL CONTEXT}

In reference to digital architectural design pedagogy, there are already examples of using both digital and physical modelling iterations methodologies within final year design studios of undergraduate architectural studies, but none in the very first year of architectural studies.

An example of advanced design regarding Generative design pedagogy in the third year of teaching architecture, is described in the book Generative Design by Agkathidis (2015). In this book, students that already had some knowledge of architecture and digital design software used for form-finding, such as Rhinoceros explored Generative Design approaches.

A pedagogical approach that focuses on the use of the diagram is discussed by Maldonado (2014) in Digital Recipes: A Diagrammatic Approach to Digital Design Methodologies in Undergraduate Architecture studios. This paper differs from these examples as it is focusing at even an earlier stage of architecture studies; the first year and requires no prior knowledge of architecture or digital design tools.

An example of digital modelling techniques in architectural studies is the textbook Digital Design Exercises for Architecture Students by Johnson \& Vermillion (2016). This paper aims to take the textbook approach a step further, proposing a method that focuses on the design thinking, regardless of the design tools used.

\section{THE METHOD}

The method was applied in design studio teaching during the whole first year of architectural studies in a UK university and is split in two phases. A part of Phase 1, was presented at the SIGraDI conference in 2016. Phase 1 focused on transformations of physical models as a way to map the design process in a controlled way, the same way any visual parametric software creates a map of interconnected design parameters that control and manipulate geometries.

During each of the two semesters of the academic year, students were asked to design their main studio project using the proposed method. The first semester-phase had three design projects and the second-semester had one design project.

Phase 1 is using maybe the most basic tool for architectural design: physical modelling. Students were asked to develop a number of spatial transformations, using only four consecutive numbered steps. They had to physically transform a specific initial geometry (a cube, a plane and a contour curve) during three design studio workshops-projects in semester 1 of their studies. Students had to transform their initial geometry (for example the cube) using verbs and commands found in most form-finding design software such as cut, split, trim, move, rotate, scale, stretch, offset, copy, paste.

This way the instructions of process are included in the process itself, as Menges (2011) discusses. The results of phase-semester 1 were a series of physical models for each of the cube, surface and contour workshops. All four transformation steps were documented with physical model photos and 2D diagrams, which mapped the design process, from initial geometry, to final result. (Figure 1).

Beyond documenting their design process probably like any other first-year design studio project- students also produced sketches, axonometrics, diagrams, as well as plans and sections, for each of the three workshops - projects. It is important to state here that the deliverables at the end of each workshop-project, were more than physical models, since the course has to comply with the RIBA and ARB requirements of teaching first-year design studios in the UK. This means that other than the design process presented here, students had to also think about pragmatic architectural issues regarding their design project, such as programmatic distribution, circulation, tectonics and materiality, to name a few.

Phase 2, like the previous phase, focuses on transformations in order to create architectural space, while mapping each of the numbered steps of the design process. The difference is that In this phase the transformations are digital and that students had to solely use a digital design software used broadly for form-finding: Rhinoceros. 
Figure 1

Numbered design steps / commands for phase 1-physical modelling iterations.

\section{PHASE 1-PHYSICAL TRANSFORMATIONS}

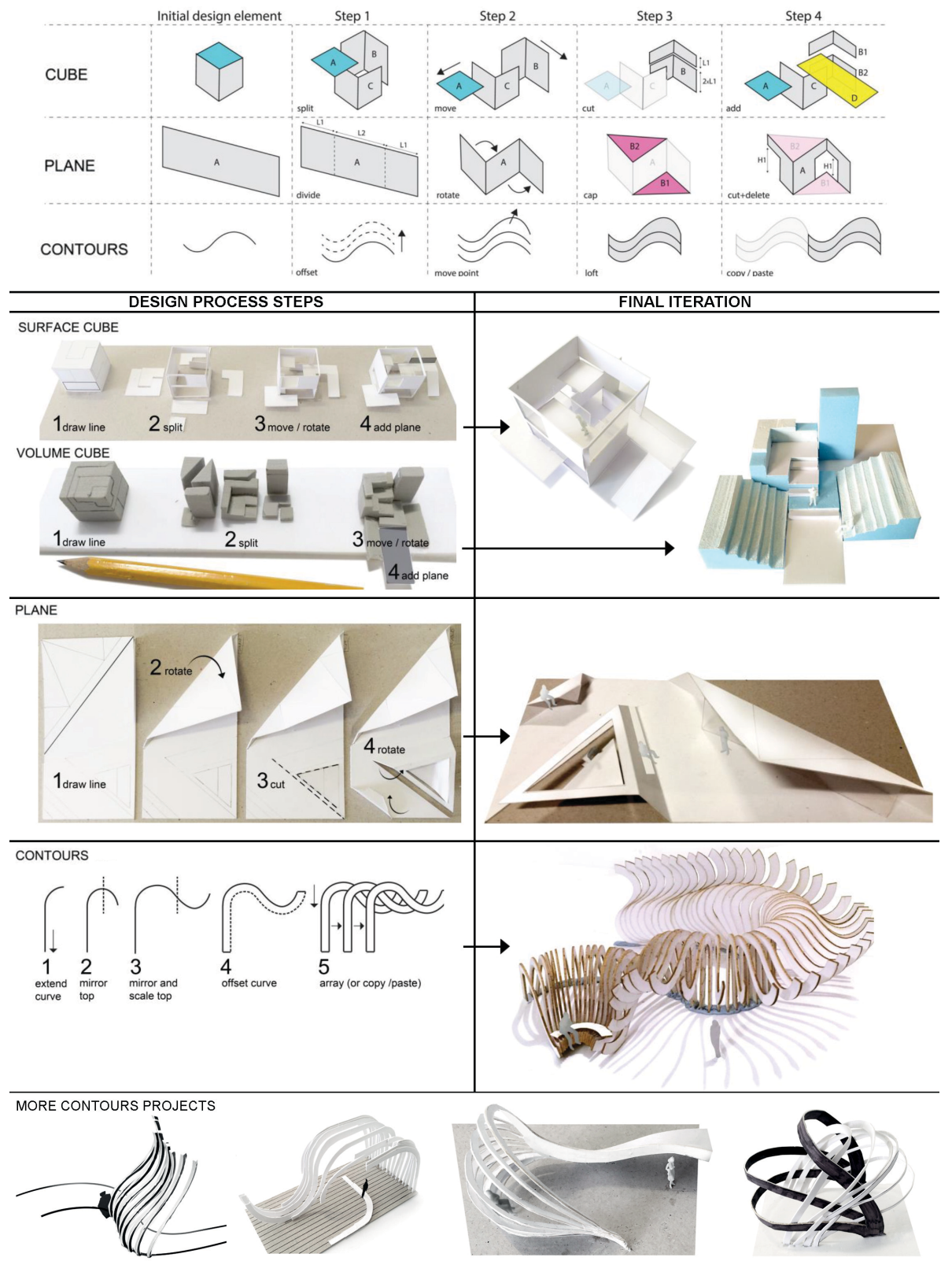

Challenges - EDUCATION AND RESEARCH - Volume 1 - eCAADe 37 / SIGraDi 23 | 95 
The students were asked to design a retail space of $150 \mathrm{~m} 2$ using the Controlled Transformations method while manipulating / multiplying, an initial geometry of either a sphere or a control point curve, using solely the Rhinoceros software. All transformations were done by using some of the commands used in semester 1 .

Students could again go back to any previous step, and iterate their design, resulting to different outcomes.This phase is using the same method of Phase 1; geometric transformations and mapping of the four design steps and instructions, but only using the Rhinoceros software.

Students could still sketch and make test physical models, but only of elements they initially designed in Rhino. This way, they had to adapt to the way the digital tool itself, the way the software, functions. And this is why the were introduced to this design thinking and the basic verb / commands in the previous semester, even when transforming physical models.

This was done in an effort to help students design a project that was not predefined in their sketchbooks, but was conceived and formed while using the software. The method is actually an effort to help students use form-finding software as a tool of architectural synthesis (Computation), instead of mere representation (Computerisation) as Terziids (2006) discusses.

It was important to have the same audience as Phase 1 (the same cohort of students) in order to test and evaluate their progression into Computational Design Thinking, based on the transition from physical, to digital modelling.

The students were introduced to basic digital modelling using the Rhinoceros software in the first two weeks of semester 2 . This was achieved through two workshops with a duration of three hours each.

At the same time, in an effort to help students understand that digital design is closely related to CAM technologies, such as 3D printing and laser cutting, they were introduced to a now broadly used construction technique: the waffle.
This means they had to add a final design step, which was to digitally model a waffle version of their blob or curved surface(s). This is a quite simple and easy step in Rhino, which can be done by the contours command or by projecting lines on any geometry. This extra step was quite important, as a way to start thinking of the tectonics and actual fabrication of complex, digitally designed surfaces, that traditional construction techniques would be too expensive to use or too time-consuming.

This part of Phase 2 was crucial in this learning method, in order to help students reconnect the digital with the physical world (their digital designs to physical scale models).

The timeframe for Phase 2 was longer than Phase 1 , in order to allow students to adjust to the Rhino software and fabrication tools. This is also why students only had one design workshop-project during this semester.

A series of digital models were produced throughout Phase 2 in semester 2, the same way diagrams and physical models where produced during Phase 1 in semester 1 (Figure 2).

At the same time, physical model versions of the project iterations were materialized, as a way to test the design aesthetically and structurally, which then informed the design as feedback, creating further digital model iterations. The CAM methods that were introduced to the students over a three-hour session, included 3D printing and laser cutting. Laser cutting their iterations allowed students to manually assemble each of the waffle flat members.

\section{EVALUATION}

The way the proposed method is evaluated, is by comparing the cohort marks to those of previous years, comments by mark moderators and comments in the anonymous student survey.

Students managed to tackle the studio's design approach and requirements quite well, even though this was the first semester term of their studies. The student performance, Personal Development forms, anonymous survey and final marks (compared to the 
Figure 2

Numbered design steps / commands for phase 2- digital modelling iterations.
PHASE 2-DIGITAL TRANSFORMATIONS

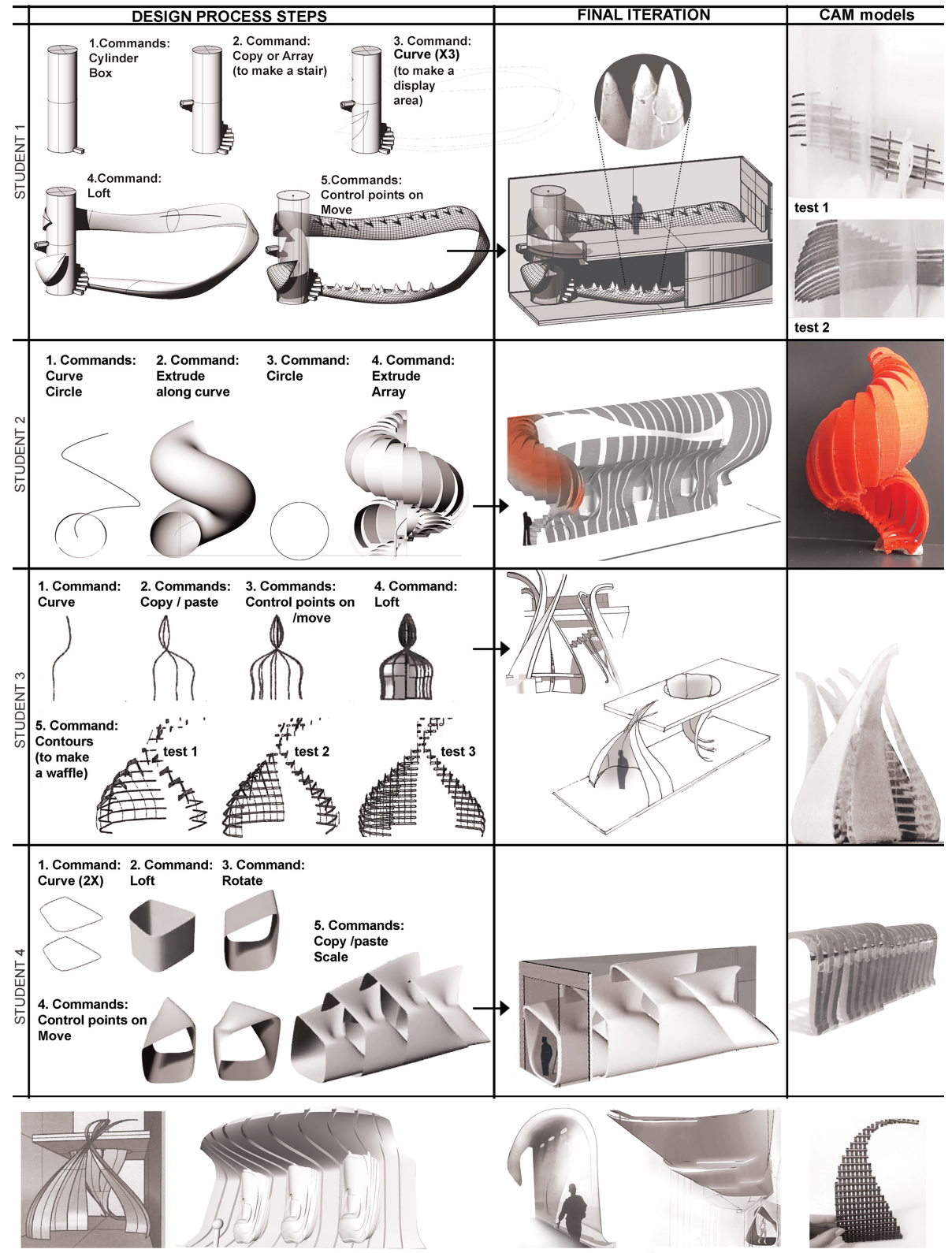


previous years) indicate a positive outcome on the proposed design method.

It is noted that students had the same amount of tutoring and design studio contact hours, as our university has had for first-year students in previous years.Looking at the student marking statistics at the end of first year, the A marks did rise 50\% compared to the previous year, due to the Controlled Transformations method. An anonymous student survey showed that $100 \%$ of the students found that these design studio workshops (combined with theory and precedents lectures) have improved their knowledge and understanding of the subject (Figure 3).

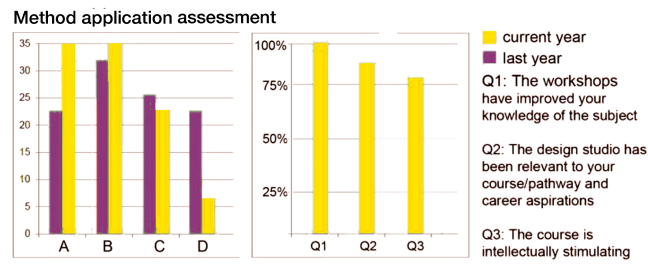

\section{CONCLUSIONS}

This method allows students to "manually" return to a previous step of the process and iterate their design, which would then result to different design outcomes, if the initial design steps - instructions - parameters are changed. During this process, each step - transformation instruction (and resulting changes on the form of the design) are documented with diagrams. The diagrams explain the instructions for each design step, either using physical or digital models. This test in first-year teaching of a design studio indicates how his method can subtly introduce students to Computational Design Thinking. And how digital design tools are actually changing the way we design architecture, even if we never choose to use any digital design tool, such as parametric software. It is a method that deserves to be investigated further.

\section{ACKNOWLEDGEMENTS}

The author would like to thank all students that contributed with their design studio projects, as well as the fellow tutors and mark moderators for their constant support and feedback.

\section{REFERENCES}

Agkathidis, A. 2015, Generative Design, Lawrence King Publishing, London

Johnson, J. and Vermillion, J. 2016, Digital Design Exercises for Architecture Students, Routledge, London

Kolarevic, B. 2003, Architecture in the Digital Age: Design and Manufacturing, Taylor\&Francis, London

Leach, N. 2009, 'Digital Morphogenesis', AD, 79(1), pp. 34-37

Lynn, G. 1999, Animate Form, Princeton Architectural Press, Princeton

Paredes Maldonado, M. 2014 'Digital Recipes: A diagrammatic approach to digital design methodologies in undergraduate architecture studios', FusionProceedings of the 32nd eCAADe Conference,Volume 1, Newcastle, pp. 333-342

Marcos, C.L. 2010 'Complexity, Digital Consciousness and Open Form: A New Design Paradigm', Proceedings Acadia 2010 (30th Annual Conference of the Association of Computer Aided Design in Architecture, New York, pp. 81-87

Menges, A. and Ahlquist, S. 2011, Computational Design Thinking (AD Reader), John Wiley \& Sons Ltd., London

Pask, G. 1969, 'The Architectural Relevance of Cybernetics', $A D, 7(6)$, pp. 494-496

Terzidis, K. 2006, Algorithmic Design, Routledge, London Thompson, D. 1917, On Growth and Form, Cambridge University Press, Cambridge

Vamvakidis, S. 2018, Composing Architecture and Interior Design, BIS, Amsterdam

Wiener, N. 1961, Cybernetics: Or the Control and Communication in the Animal and the Machine, MIT Press, Cambridge
Figure 3

(Left): Marks comparison with last year. (Right): Student comments. 